duplicate, and all the duplicates were remarkably concordant. The results were, that seeds in unheated earth began to germinate on the ninth day, the total germination being 65 per cent.; in earth heated to $250^{\circ}, 150^{\circ}$, $95^{\circ}$, and $80^{\circ}$, no germination has occurred yet, although twenty-two days have now elapsed, while in the case of earth heated to only $60^{\circ}$, germination did not occur until the eighteenth day, and the total germination is only 30 per cent.

Dr. Russell mentioned that in his experiments he had not noticed any retardation to be produced by the sterilisation of the soil; but in his experiments, as well as in my own with apple trees, no steps were taken to guard against re-inoculation from the air, and such re-inoculation would be very easy in the case of seeds just below the surface of the soil. Another explanation may be that we have not used similar seeds; and from some experiments with mustard, now in progress, it is evident that different seeds behave differently, though the difference may be due to the imperfect sterilisation of the seeds themselves in some cases. Dr. Russell has been good enough to examine my experiments whilst in progress, and I believe that he is satisfied with the results so far as they go at present.

There is not sufficient evidence yet to show whether the bacterial action is a direct one on the seeds, or whether it is an indirect one, as Dr. Russell suggested, modifying some chemical change produced in the soil by heating. The very low temperature $\left(60^{\circ}\right)$ which suffices to affect the germination tells against the view that chemical change is one of the governing factors, as also does the fact that the results obtained with sand are similar to those obtained with earth. On the other hand, it was found that with soil which had been heated to $\mathrm{I}_{5} \mathrm{O}^{\circ}$, and then reinoculated, germination was much retarded, and was very feeble, this pointing to some chemical change which was not counteracted at once by the re-inoculation.

The view that plants in growing charge the soil with something which is toxic to other plants was put forward a year or two ago by Dr. Whitney, but the evidence adduced for it seems to have been very inconclusive; the details of Mr. Fletcher's results in this direction will, therefore, be expected with considerable interest. We have, during the last three years, been endeavouring to ascertain whether any action of this sort can account for the effect of grass on trees, trees having been grown in earth or sand in pots and watered with leachings from earth or sand in which grass was growing. The results, however, have been entirely negative.

Spencer Pickering.

\section{Biological Expedition to the Birket el Qurun.}

ThE lake in the Fayum province of Egypt known as the Birket el Qurun has a very unique interest as the remains of the historic Lake Moeris, which was used as an artificial regulator of the Nile floods by the monarch of the twelfth dynasty. During the last few years a good deal of attention has been paid to the lake and the whole Fayum province by Captain Lyons, F.R.S., and the staff of the Egyptian Survey Department. No detailed examination of the flora and fauna had, however, been undertaken, and it was to furnish the desired biological information that we were invited to make investigations in the spring of this year.

The Birket el Qurun is now reached with great ease from Cairo, as the railway comes within a distance of some seven miles. Consequently we had no difficulties of transport to contend with, and began our work on the lake shore on March 26. During a period of eight weeks we made careful collections in a number of different parts of the lake, and being provided with a sailing-boat of moderate size we were able to make our way about by water, camping in a number of likely places on the shore sufficiently far apart.

The lake seems to be remarkable more for the quantity of life which its waters contain than for the number of different species inhabiting it. The tow-net revealed immense swarms of entomostraca-mostly copepods and NO. I970, VOL. 76] cladocera-as well as vast numbers of rotifers, while the smaller organisms form the food supply of the fish, which occur in astonishing abundance. Although the tow-nettings usually afforded a plentiful supply of the smaller animals, they contained relatively little in the way of phyto-plankton. Algæ were collected from the rocks and stones and the submerged stems of plants, while the larger representatives of the flora were also collected.

The fish were for the most part obtained from the native fishermen, and while some thirteen different species were brought home, the overwhelming majority of those taken belong to two species of the genus Tilapia. A large specimen of the Nile perch (Lates niloticus) was examined, which measured $120 \mathrm{~cm}$. and weighed $54 \mathrm{lb}$. Only a few species of mollusca were found, with but a single lamellibranch amongst them, while the worms are represented by certain small oligochætes. The collection contains a polyzoan with circular lophophore, while among the hydrozoa, Cordylophora is found growing abundantly. Perhaps the most interesting discovery is that of a medusa, and the hydroid form with which it is associated. While the water of the lake is now slightly brackish, there is evidence that it was perfectly fresh even in historic times, so that the existence of this form here is rendered more than ever remarkable. It is a typical anthomedusan, and finds its nearest ally in the marine genus Sarsia. There are several animal groups apparently unrepresented in the Birket el Qurun which we might well expect to find, since they are common in the Nile, with which the lake is in direct communication. Such are the crabs, prawns, and sponges, of which no specimens were procured. Similarly we obtained no examples of argulidæ, leeches, or turbellaria.

In addition to the actual collecting, certain physical observations were made. 'The seiche alterations in waterlevel appear to be very slight,: as is only natural where the greatest depth is but four or five fathoms. A number of readings of the water temperature were taken which prove unexpectedly interesting. The temperatures recorded show a maximum of $94^{\circ} \cdot 2$ in very shallow water close to shore about 2.0 p.m., and a minimum of $54^{\circ} .8$ as a surface reading in the early morning. The difference between the surface temperature and that of the water below may also be very considerable, as was shown in one case by a difference of $8^{\circ} .8$ between the reading at a fathom and that at the surface. All these figures are doubtless explained by the shallowness of the lake and the extremes of heat and cold to which it is often exposed.

W. A. Cunnington, Christ's College, Cambridge.

C. L. Boulenger, King's College, Cambridge.

\section{The Atomic Weight of Cobalt.}

It has recently been suggested by Prof. J. J. Thomson that the accepted atomic weight of cobalt, namely $59 \cdot 0$, is probably too high, and that the true atomic weight of cobalt is less than that of nickel. Prof. Thomson's suggestion was founded on the results observed with secondary radiation.

We have made an attempt to determine the atomic weight electrolytically by direct comparison with silver, and obtain as the mean of fifteen determinations a value of $5 \% .7$ for the atomic weight.

We have also attempted to compare the atomic weights of cobalt and nickel directly with each other and with that of silver by placing three voltameters in series and passing the same current through them, but on account of unexpected difficulties due to secondary reactions in the case of nicizel we have not yet obtained satisfactory results.

We hope later to complete the investigation and give details of the experiments.

One of us ("F. H. P.") has also compared the absorption of cobalt and nickel for the $\beta$ radiation from uranium, and the results indicate a smaller atomic weight for cobalt than for nickel.

F. H. PARKER. F. Peake Sexton.

Physical Laboratories, Woolwich Polytechnic. 